\title{
Sexual Dysfunction in Women with Diabetes: Counseling intervention
}

\author{
Tereza Khalifa ${ }^{1}$, Ragaa Ali Mohamed ${ }^{2,}$ Soad Abd EI Salam Ramadan ${ }^{3}$ and Hend Abdallah \\ Elsaid Afify ${ }^{4}$ \\ ${ }^{l}$ (Maternal\& Newborn Health Nursing, Faculty of Applied Medical Science / October 6 University, \\ Egypt) \\ ${ }^{2}$ (Maternal\& Newborn Health Nursing, Faculty of Nursing / Cairo University, Egypt) \\ ${ }^{3}$ (Obstetrics and Woman's Health Nursing , Faulty of Nursing - Benha Universit, Egypt) \\ ${ }^{4}$ (Obstetrics and Woman's Health Nursing , Faulty of Nursing - Benha Universit, Egypt)
}

\section{Abstract:}

Background: Sexual dysfunction is common gynecological complaint among diabetic women due to its complication effect on sexual function. Aim of this study: Examine the effect of counseling session on female sexual dysfunction regarding diabetic female. Research design: A quasi-experimental design was utilized to carry out this study. Sample: A purposive sample of 132 diabetic women who had sexual dysfunction was recruited in this study. Setting: The study was carried out at six October University Hospital which located at Giza. Tools of data collection: Two tools were used to collect data: (1) Structure interviewing questionnaire to assess female demographic data, medical history and the obstetrical and sexual history (2) Female Sexual Function Index (FSFI): The FSFI is a validated 19-item, self-administered, screening questionnaire that measures the aspects of sexual function in women (desire, arousal, lubrication, orgasm satisfaction, and pain). Results: The result showed that the mean age of the participant was $34.17 \pm$ 5.5 years. There was no significant relation between some factors such as age, duration of diabetes, marital characteristics, and frequency of sexual dysfunction. Most of participants had enhancement of total FSFI scores post counseling intervention compared to pre counseling intervention Conclusion: Counseling intervention have positive effect on the sexual function enhancement among diabetic female. Recommendation: This study recommended carry out further researches to explore the relations between diabetes and female sexual dysfunction to determine the possible pathway of this association and increase awareness of Egyptians about sexuality through counseling session.

Keywords: Female sexual dysfunction, Female sexual function index, Diabetes mellitus, PLISSIT model

\section{Introduction}

Diabetes mellitus is a chronic metabolic disease characterized by insulin deficiency and/or resistance (Fatima, Miyan, Naeem, Riaz, \& Basit, 2020). Diabetes mellitus is a main health problem all over the world. In 2010, it has been estimated that more than 200 million people suffer from it. The worldwide population is expected to increase by $62 \%$, and the prevalence of diabetes mellitus is expected to increase by over 120\% (Ahmed, Gad \& Al-Adlany, 2020).

\section{The International Diabetes} Federation Atlas, (2017) reports a prevalence of $8.8 \%$ around the globe Four out of five diabetics live in middle- or low-income countries with MENA region leading the 
prevalence table with almost $11 \%$. The global prevalence has nearly doubled since 1980. World Health Organization, (2016) showing a scary doubling rate as compared to other non-communicable diseases worldwide. It is estimated that the prevalence of diabetes will rise to 591.9 million by the year 2035 , while Pakistan currently out of the top 10 countries will be on the 8th spot with 12.8 million diabetics in 2035.

The International Diabetes Federation (IDF) listed Egypt among the world top 10 countries in the number of patients with diabetes. It is expected that the number of patients with diabetes in the Middle East and North Africa region to grow by $96 \%$ from the year 2013 to 2035 or from 34.6 million to 67.9 million. In Egypt, the prevalence of diabetes is around $15.56 \%$ among adults between 20 and 79 years of age, with an annual death of 86,478 related to diabetes (Mohammed, 2020).

In 2013, the IDF estimated that 7.5 million individuals have diabetes and around 2.2 million have prediabetes in Egypt. Furthermore, reports indicate that $43 \%$ of patients with diabetes and most patients with prediabetes in Egypt are likely undiagnosed. It is alarming that diabetes prevalence in Egypt has increased rapidly within a relatively short period from approximately 4.4 million in 2007 to 7.5 million in 2013. It is expected this number will jump up to 13.1 million by 2035 (Al-Rubeaan 2010; Jain and Saraf 2010; Whiting et al., 2011; Bandeira et al., 2013; I.D.Federation 2015 ), Consequently, the complications associated with the disease are also expected to increase. These include microvascular complications such as neuropathy, nephropathy and retinopathy and macrovascular complications such as peripheral artery disease, stroke and cardiovascular diseases (Fatima, Miyan, Naeem, Riaz, \& Basit, 2020).

One of the long-term complications of diabetes is sexual dysfunction, Sexual health is the result of interaction of cardiovascular, neurological, and hormonal factors and is influenced by individual factors, interpersonal relationships, traditions governing family and community, culture, and religion (Ogbera et al., 2009).

Diabetes is seen to be a risk factor of female sexual dysfunction because the normal female sexual response needs the integrity of the sensory and autonomic nervous system to response to erotic stimuli, as well as of the vascular integrity which supply the external genitalia and vagina which affected by hyperglycemia (Maiorino, Bellastella, \& Esposito, 2020), Complications of diabetes in women has adverse effects on their selfimage, quality of life, health and other social relationships, thereby affecting their sexual performance (Ogbera et al., 2009).

Female sexual dysfunction is defined by Rahmanian, Salari, Mohammadi, \& Jalali, (2019), under international classification of diseases, as “a woman's inability to experience sexual intercourse as she would wish. Sexual dysfunction is a heterogeneous combination of disorders that is characterized as a major disorder in one's ability to respond to sexual response or sexual pleasure. These disorders include abnormalities in women's orgasm, arousal, pain, and unknown sexual dysfunction, although various studies have reported high prevalence of sexual dysfunction in women with diabetes compared with non-diabetic women (Rahmanian, Salari, Mohammadi, \& Jalali, 2019). 
The maternity nurse care can play a critical role as a sex educator and sex counselor in this context; also she has an important role to assess the knowledge about needs for sexual health (Khedr, \& Metwally, 2018). Numerous frameworks are available for sexual advice that can help nurse to implement appropriate and effective support strategies for intervention in the cases of sexual concerns and problems such as ALARM, BETTER, PLEASURE and PLISSIT. These models all take a somewhat different approach to sexual counseling (Wright, \& Gros, 2010; Lamont et al. 2012; Quinn, \& Happell, 2012).

Sexual PLISSIT model is the most commonly used tool for studying and evaluating sexual function and can be used by all people. This model was developed by psychologist Jack Annon (1974) to be used by healthcare providers in visits to assess the patients' sexual health needs (Annon J., 1981).

Sexual PLISSIT model is the sexual counseling model has a four stage framework, including a patient permission to start talking about sexual problems, providing limited information, specific suggestions, and intensive care to resolve the sexual problems of the patients. This counseling model has been studied in patients with stoma, breast cancer, multiple sclerosis, uterine, and vaginal cancer, as well as in patients undergoing surgeries such as hysterectomy or cardiac surgery and in all of these patients, it has been proven useful in solving and managing patients' sexual problems (Rezaei-Fard, Lotfi, Rahimzadeh, \& Merghati-Khoei, (2019).

Regarding the high prevalence of diabetic patients' sexual problems, it seems that diagnosis of sexual problems and counseling about these problems with patients should be more carefully planned in the healthcare system. In some other countries also, health services often are not organized for the needs of diabetic patients, and health workers lack the knowledge and skills to manage such diseases (Mehrabi, Lotfi, Rahimzadeh, \& Khoei, 2019).

\section{Significant of the study:}

A healthy sexual relationship is one of life's expectations and pleasures. When things go wrong, whether or not we have diabetes, many of us find it hard to accept that there might be a problem that may need to be treated. It's important to know this isn't something you need to face alone as there is a great deal of available support. Diabetes seem to impair women's normal sexual functioning, recent, evidence indicates that diabetic women are at higher risk for developing sexual dysfunction compared to those without diabetes. Nurses play a key role in promote of health condition and prevent any complications with proper management of women who experience sexual dysfunction. Health education about warning symptoms is also important because early recognition may help women receive treatment and prevent complications of the disease. Follow-up may be necessary to safeguard women's physical and psychological wellbeing. Nurse should be aware of problem and address issues of sexuality when they care women with diabetes. Thus treatment of sexual dysfunction of diabetic women includes life style changes, optimal diabetic control, and psychotherapy. There is evidence that people affected with the diseases often have inadequate knowledge about the nature of diabetes, its risk factors and associated complications. Thus this study will conduct to 
examine the effect of PLISSIT counseling model on sexual dysfunction for diabetes women

\section{Aim of this study:}

The aim of the current study is to examine the effect of counseling session on FSD regarding diabetic female.

\subsection{Research hypothesis :}

Diabetic women who will receive counseling session will be more able to solve the sexual dysfunction problem than those who don't.

\section{MAterial ANd Methods}

\subsection{Research Design:}

A quasi-experimental research design used to carry out this study.

\subsection{Setting:}

The study was conducted at diabetic out-patient clinic afflicted to October 6 University Hospital, this particular setting was chosen because it is the main hospital has special unite for provide maternity care for women with high risk pregnancy such as diabetic patient.

October 6 University Hospital is one of the first hospitals in $6^{\text {th }}$ of October city, is equipped with advanced equipment in the field of medical care. The hospital has a capacity of 360 beds, $20 \%$ of which is dedicated to hospital serves the colleges of humane medicine, dentistry, applied medical science and physiotherapy. It has outpatient clinics in various specialties.

\section{3 sample:}

A purposive sample of 132 diabetic women were assigned according to the following criteria:

1. Married women who diagnosed with diabetes, sexually active at last three months and reported to or has sexual dysfunction problem / problems.

2. Age from 25-45 years.

3. No pregnancy.
4. Willing to participate in the study.

5. Can read \& write.

6. No medical or obstetric risk factor except diabetes.

1.4 Tools of Data Collection: Two tools were used in the current study to collect the necessary date.

\subsubsection{Tool (1):}

Structure interviewing questionnaire design by the researcher to collect data pertinent to the current study.

The components of the tool (1) are as follows: (A)Socio demographic data sheet: That will be cover participant code number, age, occupation, and education.

Part (B): Medical history including, onset \& duration of diabetes and type of medication.

Part (C): Obstetric history including marital age, duration of marriage, number of pregnancy, number of abortion, number of labor and mode of delivery.

1.4.2 Tool (2): Female Sexual Function Index (FSFI): The FSFI is a validated 19item, self-administered, screening questionnaire that measures the aspects of sexual function in women (desire, arousal, lubrication, orgasm satisfaction, and pain). Questions are grouped in six domains: desire (items 1 and 2), arousal (items 3-6), lubrication (items 7-10), orgasm (items 1113), satisfaction (items 14-16) and pain (items 17-19). Responses to each question were reported and scored on $0-5$ scale with 0 representing no sexual activity and 5 suggestive of normal sexual activity. For our study, an Arabic translation was used.

\section{Methods}

\subsection{Approval}

Before the conduction of this study a written approval from the responsible authority of the October 6 university 
educational hospital after clarification of aim of the study to collect necessary data.

\subsection{Pilot of the study:}

A pilot study was carried out on sample of 10 married women with DM excluded from the sample to test the feasibility of the study and applicability of the tool.

The main purpose of the pilot was to:

- Test the relevance and applicable of assessment sheet

- Detect any problem peculiar to the tools

- Determine the time needed to finish sheet

- Find out any problem that may interfere with the process of data collection

The pilot study revealed that statements of the question were relevant.

\subsection{Tool Validity and Reliability:}

Tools for data collection were developed after reviewing the related literature than these tools were tested for content validity.

The aim of the study was explained to each participant then verbal consent for participant in the study was obtained.

\subsection{Collection of data:}

The research selected diabetic women with sexual problems who fulfilled the criteria from previously mentioned setting. The research explained the purpose of the study to each woman and then verbal consent to participant in the study was obtained from each woman. Participant in the study was obtained from each woman. Each women participant was individually interviewed on admission to the separate room \& in total privacy to assure that information to be obtained well be confidential and will be used only for the purpose of the research in order to collect data for help women to solve her problem.

\subsection{Procedure of the study:}

The study proceeds as follows: Assessment phase:

$>$ Data collected during 8 months started from August 2017 to October 2018. The researcher visited the diabetes outpatient clinic from 9.00 am to $1.00 \mathrm{pm}$ for 2days per week. The number of interviewed women per week was 10-12 women. The average time taken for each woman around 20-30 minutes depending on the response of the woman.

$>$ The participant women were fill interviewing questionnaire and female sexual function index (FSFI) questionnaire to assess their sexual functions.

$>$ The researcher clarified anything to participants were fill the questionnaire.

\section{Planning phase:}

$>$ The researcher used a well-prepared intervention material and contents in the form of comprehensive PowerPoint presentation related to diabetes, normal female sexual response, and female sexual dysfunction and how deal with it.

$>$ The counseling was conducted by using PLISSIT model which developed by psychologist Jack Annon."PLISSIT" is an acronym for the four levels of intervention, which include Permission (P), Limited Information (LI), Specific Suggestions (SS), and Intensive Therapy (IT).

\section{Implementation phase:}

The PLISSIT model is used for discussing women sexuality status and determines their problems. This model provides steps 
approach to sexual problems of the individual. These steps include:

a) Permission:

Diabetic women provided a permission to talk about the sexual issues (sexual feeling and problem).at these step, the researcher demonstrate active listening, freely interacted with the women, simply asked question about all aspects of sexual status and what it means to her and identify any concern.

b) Limited information:

The researcher offered brief information to the women about the relation between diabetes and sexual function and the effect of uncontrolled diabetes on sexual statues, the researcher focused on addressing and correcting misinformation about sexual problems.

c) Specific suggestion:

The researcher assists the women with very specific direction on how to address the problem. Then offered specific suggestions the women what she can do for her sexual problem as enhance sexual desire, decrease vaginal pain and how to maintain vaginal lubricant (including regular daily walks, recommendations for taking lubricant, sensate focus, and changes in sex position).

d) Intensive therapy:

The researcher in this stage inform the women about services to which women can be referred for more intensive or comprehensive treatment (sex therapist, psychologist, social worker, medical specialist)

\section{Evaluation phase:}

- Evaluation of effect of counseling session on female sexual function done by using female sexual function index was measured once before counseling session and twice time after counseling session and finally research compared between them.

- The researcher followed up women and communicates with them via telephone call for any structure and determines the next session.

\subsection{Statistical Analysis Data}

Upon completion of data collection, data were analyzed using SPSS program version 20; then tabulated. Relevant statistical analysis was used to test the obtained data. Descriptive and inferential statistics were done such as mean and standard deviations; frequency; percentage; chi square test; and independent $\mathrm{t}$ test \& ANOVA analysis of variance.

\section{Result}

Result showed that, the age of studied women was ranged between 26-45 years, with a mean age of (34.17 \pm 5.5$)$ years. Considering women's education level. The result revealed that secondary school education represented the higher percent by $43.9 \%$ followed by those who had read and write $(27.3 \%)$. Also the result reported that nearly two thirds of studied women were house wife $(63.6 \%)$ (table 1).

Table (2) shows present medical history of the studied women related to diabetes. Regarding duration of diabetes, more than two third $(67.4 \%)$ of studied women were suffer from diabetes from more than 10 years. Among all diabetic women, it was found that more than one quarter $(29.5 \%)$ of studied women was suffered from diabetic end organ complication. Renal complication was $10.6 \%$, followed by retinopathy $(8.3 \%)$, peripheral neuropathy $(6.8 \%)$, and finally $3.8 \%$ were poor peripheral circulation. More than half $(53.0 \%)$ of studied women were oral medication and diet control-treated diabetic. as regards of control diabetes show that nearly 
three fifths $(59,1)$ had well controlled diabetes and about two fifths (40.9.0\%) of studied women were poorly controlled.

Table (3) denotes that the mean of marital age of studied women was $20.9 \pm$ 3.5years. Regarding to duration of marriage, more than half of studied women $(57.6 .0 \%)$ were married from more than ten years. More than two thirds $(71.2 \%)$ of studied women get pregnant ranged between one to three times, regarding to occurrence of abortion, more than four fifths $(83.3 \%)$ didn't aborted, as regard to parity number, three quarters (75\%) of studied women delivered from one to three times. Considering mode of delivery, the result denoted that about two thirds $(62.9 \%)$ of studied women had vaginal delivery.

Figure (1): Regarding to regularity of women sexual intercourse figure (1) revealed that the more than four fifths $(84 \%)$ of the studied women performed regular sexual intercourse (not less than once per month), compared to $16 \%$ were not practice sexual intercourse regularly.

Table (4) shows sexual dysfunction among the studied women related to diabetes. Regarding desire domain it noticed that more than four fifths $(86.4 \%)$ of studied women were suffer from desire dysfunction, in relation to arousal, lubricant, orgasm and pain domains, the present studied represent that the majority of studied women had arousel problem $(97 \%)$, orgamic problem $(98,5)$, lubricant problem $(98.5 \%)$ and pain (97\%) and more than more than four fifths (87.9.0\%) of studied women did not satisfied in their sexual relationship.

Table (5) illustrates that no significant relations were determined between sexual function and age, education, occupation ( $\mathrm{p}>$ $0.05)$.

Table (6) shows the relation between FSFI total scores of studied sample and present medical history of diabetes. No significant differences were detected between sexual function, diabetes duration, and treatment methods and glucose control ( $\mathrm{p}>$ $0.05)$.

Table (7) elaborates that there was a highly statistically significant difference in total FSFI Scores pre intervention with Mean \pm SD $20.71 \pm 4.42$ compared to post intervention with Mean \pm SD $30.39 \pm \mathbf{3 . 3 2}$ at $\mathrm{p} \leq 0.001$. 
Table (1) Distribution of studied women according to their socio-demographic characteristics $(n=132)$.

\begin{tabular}{|c|c|c|}
\hline Socio-demographic characteristics & No. & $\%$ \\
\hline $\begin{array}{l}\text { Age group: (years) } \\
25- \\
30- \\
35- \\
40-45\end{array}$ & $\begin{array}{l}27 \\
54 \\
28 \\
23\end{array}$ & $\begin{array}{l}20.5 \\
40.9 \\
21.2 \\
17.4\end{array}$ \\
\hline Mean \pm SD & \multicolumn{2}{|c|}{$34.17 \pm 5.5$} \\
\hline $\begin{array}{l}\text { Educational Level: } \\
\text { Illiterate } \\
\text { Read and Write } \\
\text { Primary Education } \\
\text { Secondary Education } \\
\text { Bachelor }\end{array}$ & $\begin{array}{c}11 \\
36 \\
7 \\
58 \\
20 \\
\end{array}$ & $\begin{array}{c}8.3 \\
27.3 \\
5.3 \\
43.9 \\
15.2 \\
\end{array}$ \\
\hline $\begin{array}{l}\text { Occupation: } \\
\text { Employed } \\
\text { Housewife }\end{array}$ & $\begin{array}{l}48 \\
84\end{array}$ & $\begin{array}{l}36.4 \\
63.6\end{array}$ \\
\hline $\begin{array}{l}\text { Age of marriage: (years) } \\
\text { Less than } 20 \text { years } \\
20-30 \\
31-40\end{array}$ & $\begin{array}{c}71 \\
58 \\
3\end{array}$ & $\begin{array}{c}53.8 \\
43.9 \\
2.3\end{array}$ \\
\hline Mean \pm SD & & \\
\hline $\begin{array}{l}\text { Duration of marriage: (years) } \\
\text { 1-5 years } \\
6 \text {-10 years } \\
\text { More than } 10 \text { years }\end{array}$ & $\begin{array}{c}2 \\
54 \\
76 \\
\end{array}$ & $\begin{array}{r}1.5 \\
40.9 \\
57.6 \\
\end{array}$ \\
\hline Mean \pm SD & & \\
\hline $\begin{array}{l}\text { Number of pregnancy: } \\
\text { Non } \\
1-3 \\
>3\end{array}$ & $\begin{array}{c}5 \\
94 \\
33\end{array}$ & $\begin{array}{c}3.8 \\
71.2 \\
25\end{array}$ \\
\hline $\begin{array}{l}\text { Number of abortion } \\
\text { Non } \\
1-2\end{array}$ & $\begin{array}{c}58 \\
110 \\
22\end{array}$ & $\begin{array}{l}43.9 \\
83.3 \\
16.7\end{array}$ \\
\hline $\begin{array}{l}\text { Number of delivery: } \\
\text { Non } \\
1-3 \\
>3\end{array}$ & $\begin{array}{c}5 \\
99 \\
28\end{array}$ & $\begin{array}{c}3.8 \\
75 \\
21.2\end{array}$ \\
\hline $\begin{array}{l}\text { Mode of delivery } \\
\text { Vaginal delivery } \\
\text { Caesarean section }\end{array}$ & $\begin{array}{l}83 \\
44\end{array}$ & $\begin{array}{l}62.9 \\
33.3\end{array}$ \\
\hline
\end{tabular}


Table (2) distribution of studied women according to their medical history $(n=132)$

\begin{tabular}{|c|c|c|}
\hline Medical history of the studied women & No. & $\%$ \\
\hline \multicolumn{3}{|l|}{ Duration of diabetes: } \\
\hline 1 - years & 17 & 12.9 \\
\hline 5- years & 26 & 39.7 \\
\hline 10- years & 89 & 67.4 \\
\hline \multicolumn{3}{|l|}{ Glucose control: } \\
\hline Yes & 78 & 59.1 \\
\hline No & 54 & 40.9 \\
\hline \multicolumn{3}{|l|}{ Diabetic end -organ complication: } \\
\hline Yes & 39 & 29.5 \\
\hline No & 93 & 70.5 \\
\hline \multicolumn{3}{|l|}{ Diabetic end -organ complication: } \\
\hline Peripheral neuropathy & 9 & 6.8 \\
\hline Retinopathy & 11 & 8.3 \\
\hline Renal complication & 14 & 10.6 \\
\hline Poor circulation & 5 & 3.8 \\
\hline \multicolumn{3}{|l|}{ Treatment of diabetes: } \\
\hline Diet control & 5 & 3.8 \\
\hline Oral medication & 26 & 19.7 \\
\hline Inject able (Insulin) & 9 & 6.8 \\
\hline Diet control + Oral medication & 70 & 53.0 \\
\hline Oral medication + Exercise + Diet control & 15 & 11.4 \\
\hline Diet control + Insulin & 7 & 5.3 \\
\hline
\end{tabular}


Table (3) Distribution of studied women according to their obstetrics history $(n=132)$.

\begin{tabular}{|c|c|c|}
\hline Marital characteristics & No. & $\%$ \\
\hline Age of marriage: (years) & & \\
\hline Less than 20 years & 71 & 53.8 \\
\hline $20-$ & 58 & 43.9 \\
\hline $30-$ & 3 & 2.3 \\
\hline Mean \pm SD & \multicolumn{2}{|c|}{$20.9 \pm 3.5$} \\
\hline \multicolumn{3}{|l|}{ Duration of marriage: (years) } \\
\hline 1- years & 2 & 1.5 \\
\hline 5- years & 54 & 40.9 \\
\hline $10+$ years & 76 & 57.6 \\
\hline Mean \pm SD & \multicolumn{2}{|c|}{$13.2 \pm 6.0$} \\
\hline \multicolumn{3}{|l|}{ Number of pregnancy: } \\
\hline Non & 5 & 3.8 \\
\hline $1-3$ & 94 & 71.2 \\
\hline$>3$ & 33 & 25 \\
\hline Number of abortion & 58 & 43.9 \\
\hline Non & 110 & 83.3 \\
\hline $1-2$ & 22 & 16.7 \\
\hline \multicolumn{3}{|l|}{ Number of delivery : } \\
\hline Non & 5 & 3.8 \\
\hline $1-3$ & 99 & 75 \\
\hline$>3$ & 28 & 21.2 \\
\hline \multicolumn{3}{|l|}{ Mode of delivery } \\
\hline Vaginal delivery & 83 & 62.9 \\
\hline Caesarean section & 44 & 33.3 \\
\hline
\end{tabular}




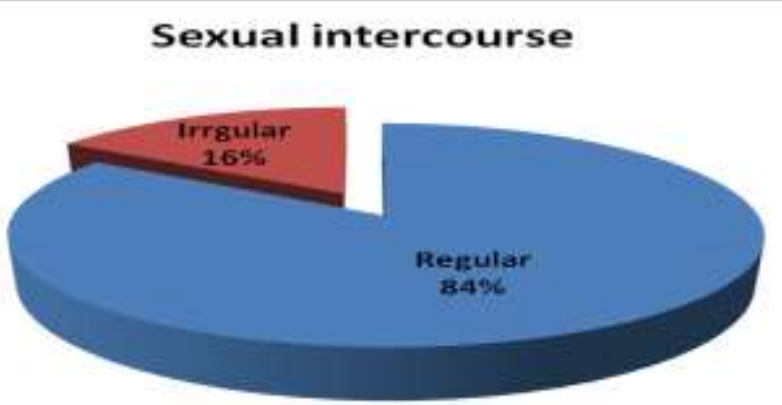

Figure (1): Distribution of studied women according to regularity of their practice sexual intercourse $(\mathbf{n}=132)$.

Table (4) Distribution of the studied sample according to their sexual dysfunction $(n=132)$.

\begin{tabular}{|l|c|c|c|}
\hline \multirow{2}{*}{ Sexual dysfunction among diabetic women } & \multicolumn{1}{c|}{} \\
\cline { 2 - 4 } & Yes & N & \% \\
\hline \multirow{2}{*}{ Desire dysfunction } & No & 114 & 86.4 \\
\hline \multirow{2}{*}{ Lubrousal dysfunction } & Yes & 128 & 13.6 \\
\cline { 2 - 4 } & No & 4 & 97.0 \\
\hline \multirow{2}{*}{ Orgasm dysfunction } & Yes & 130 & 3.0 \\
\cline { 2 - 4 } & No & 2 & 98.5 \\
\hline \multirow{2}{*}{ Satisfaction dysfunction } & Yes & 130 & 1.5 \\
\cline { 2 - 4 } & No & 2 & 98.5 \\
\hline Pain dysfunction & Yes & 116 & 1.5 \\
\cline { 2 - 4 } & No & 16 & 87.9 \\
\cline { 2 - 4 } & Yes & 128 & 12.1 \\
\cline { 2 - 4 } & No & 4 & 97.0 \\
\hline
\end{tabular}

Table (5) Relation between FSFI total scores of studied sample and sociodemographic characteristics:

\begin{tabular}{|c|c|c|c|c|c|}
\hline \multirow{2}{*}{\multicolumn{2}{|c|}{ Sociodemographic characteristics }} & \multicolumn{2}{|c|}{ Total FSFI's Scores } & \multicolumn{2}{|c|}{ ANOVA or T-Test } \\
\hline & & $\mathbf{N}$ & Mean \pm SD & $\mathbf{F} / \mathbf{T}$ & P-value \\
\hline \multirow{4}{*}{ Age } & $26-29$ years & 27 & $20.28 \pm 4.32$ & \multirow{4}{*}{.775} & \multirow{4}{*}{.510} \\
\hline & $30-35$ years & 54 & $21.31 \pm 3.65$ & & \\
\hline & $36-40$ years & 28 & $19.85 . \pm 5,44$ & & \\
\hline & 41-45 years & 23 & $20.90 \pm 4.92$ & & \\
\hline \multirow{5}{*}{ Education } & Illiterate & 11 & $21.42 \pm 3.71$ & \multirow{5}{*}{1.298} & \multirow{5}{*}{.274} \\
\hline & Read and Write & 36 & $19,69 \pm 3.89$ & & \\
\hline & Primary Education & 7 & $18,61 \pm 1.93$ & & \\
\hline & Secondary Education & 58 & $21.19 \pm 4.44$ & & \\
\hline & Bachelor & 20 & $21,54 \pm 5.85$ & & \\
\hline \multirow{2}{*}{ Occupation } & Employed & 48 & $20.35 \pm 4.12$ & \multirow{2}{*}{.711} & \multirow{2}{*}{.478} \\
\hline & Housewife & 84 & $20.93 \pm 4.60$ & & \\
\hline
\end{tabular}


Tereza Khalifa, Ragaa Ali Mohamed, Soad Abd EI Salam Ramadan and Hend Abdallah Elsaid

Table (6) Relation between FSFI total scores of studied sample and present medical history:

\begin{tabular}{|c|c|c|c|c|c|}
\hline \multirow{2}{*}{\multicolumn{2}{|c|}{ Medical history of studied women }} & \multicolumn{2}{|c|}{ Total FSFI's Scores } & \multicolumn{2}{|c|}{ ANOVA or T-Test } \\
\hline & & & & & \\
\hline Duration of diabetes & $\begin{array}{l}\text { 1-5 years } \\
6-10 \text { years } \\
\text { More than 10years }\end{array}$ & $\begin{array}{l}17 \\
26 \\
89\end{array}$ & $\begin{array}{c}21,20 \pm 3.52 \\
20.86 \pm 4.43 \\
20,58 \pm 4.61\end{array}$ & .152 & .859 \\
\hline Glucose control & $\begin{array}{l}\text { Yes } \\
\text { No }\end{array}$ & $\begin{array}{l}78 \\
54\end{array}$ & $\begin{array}{l}20.66 \pm 4.50 \\
20.81 \pm 4.37\end{array}$ & .194 & .847 \\
\hline Treatment of diabetes & $\begin{array}{l}\text { Diet control } \\
\text { Oral medication } \\
\text { Inject able (Insulin) } \\
\text { Diet control + Oral medication } \\
\text { Oral medication + Exercise + } \\
\text { Diet control } \\
\text { Diet control + Insulin }\end{array}$ & $\begin{array}{c}5 \\
26 \\
9 \\
70 \\
15 \\
7 \\
7\end{array}$ & $\begin{array}{r}21.92 \pm 3.37 \\
19.28 \pm 3.98 \\
19.71 \pm 4.37 \\
20.98 \pm 4.62 \\
20.85 \pm 4.58 \\
23.67 \pm 3.46\end{array}$ & $1 . .412$ & 0.224 \\
\hline $\begin{array}{l}\text { Diabetic end -organ } \\
\text { complication }\end{array}$ & $\begin{array}{l}\text { Yes } \\
\text { No }\end{array}$ & $\begin{array}{l}39 \\
93\end{array}$ & $\begin{array}{l}21.86 \pm 2.26 \\
20.62 \pm 4.55\end{array}$ & .848 & .398 \\
\hline
\end{tabular}

Table (7) Mean scores of total female sexual function domains (FSFI) pre and post intervention $(n=132)$.

\begin{tabular}{|c|c|c|c|c|c|}
\hline \multirow{2}{*}{$\begin{array}{c}\text { FSFI main } \\
\text { domain scores }\end{array}$} & $\begin{array}{c}\text { Pre intervention } \\
\quad(n=132) \\
\end{array}$ & $\begin{array}{l}\text { Post one month } \\
\quad(n=132)\end{array}$ & $\begin{array}{l}\text { Post three month } \\
\quad(n=132)\end{array}$ & \multirow{2}{*}{$\begin{array}{l}\text { ANOVA } \\
\mathbf{f}\end{array}$} & \multirow{2}{*}{ P-value } \\
\hline & Mean \pm SD & Mean \pm SD & Mean \pm SD & & \\
\hline Desire & $3.36 \pm 0.99$ & $4.72 \pm 0.91$ & $5.06 \pm 0.79$ & $129.926^{*}$ & $0.000^{*}$ \\
\hline Arousal & $3.18 \pm 0.93$ & $4.57 \pm 0.84$ & $4.93 \pm 0.74$ & $159.204^{*}$ & $0.000^{*}$ \\
\hline Lubrication & $3.50 \pm 0.90$ & $4.90 \pm 0.71$ & $5.19 \pm 0.64$ & $189.562^{*}$ & $0.000^{*}$ \\
\hline Orgasm & $3.32 \pm 0.89$ & $4.63 \pm 0.72$ & $4.94 \pm 0.56$ & $179.056^{*}$ & $0.000^{*}$ \\
\hline Satisfaction & $3.87 \pm 0.99$ & $4.96 \pm 0.77$ & $5.19 \pm 0.69$ & $95.081^{*}$ & $0.000^{*}$ \\
\hline Pain & $3.53 \pm 1.12$ & $4.76 \pm 0.70$ & $5.05 \pm 0.76$ & $109.895^{*}$ & $0.000^{*}$ \\
\hline Total FSFI & $20.71 \pm 4.42$ & $28.94 \pm 4.07$ & $30.39 \pm 3.32$ & 228.439* & $0.000^{*}$ \\
\hline
\end{tabular}

**: Highly significant at $\mathrm{p} \leq 0.001$ 


\section{Discussion}

The aim of the current study to examine the effect of counseling on female sexual disorder (FSD) on diabetic female. according to the results yield by the present study, the age of sample was ranged between $26-45$ years, with a mean age of $(34.17 \pm 5.5)$ years (table 1), this finding was in accordance with Udo, Effiong, Edet, Aniedi, Morgan (2019) who reported that one third of diabetic older than 34 years complain from sexual dysfunction while women below 30 years mild complain of sexual dysfunction. Also study done by Amanyam, Yohanna, \& Obilom, (2016) stated that diabetic female sexual dysfunction is age prevalence affecting between 30-50 years. Also in Abou Khodair, Al-Wafa, Othman, \& Rotab, (2019) study to assess the prevalence of female sexual dysfunction among women of Damietta governorate, among 500 selected women, the mean age was (32.95 \pm 7.1 years), majority (42.4\%) of participants were between (30-39) years, $(35,8 \%)$ were between (21-29) years while $20.6 \%$ were from 39-49 years age group and $1.2 \%$ was less than 20 years old.

Regarding to educational level the finding revealed that slightly more than one third of women (43.9\%) had secondary school while less than $10 \%$ were illiterate women, this finding was in accordance with Fatemi, \& Taghavi, (2009) who reported Thirty-two percent of subjects had primary school education, $36 \%$ had high school education and $20 \%$ had a university education., the study done with Zhang, Brown, Vistisen, Sicree, Shaw et al. (2014) disagree with the result of this study regarding to level of education, who mentioned that there were no statically significant difference between women who are highly educated and women who less educate in their complication from sexual dysfunction with diabetes
In relation to duration of diabetes it was found that more than two thirds of the sample had diabetes since 10 year or more. These results supported by Elyasi, Kashi, Tasfieh, Bahar, \& Khademloo, (2015) who reported that the variation of total score of women with sexual desire related to duration of diabetes that is means women who had long history of diabetes more complain from sexual dysfunction problem than women who had short duration.

In relation to complication of diabetes in the current study, it was found that more than one quarter $(29.5 \%)$ of patient had suffered from diabetic end organ complication such as renal complication (table 2), while the study done by Mazilli, Imbrogno, Elia et al. (2015) about Sexual dysfunction in diabetic women, prevalence and differences in type I and type 2 diabetes mellitus. Diabetes metab Synd Obes. (2015); disagreed with result of current study which reported that diabetic complications such as retinopathy and neuropathy were not recorded adding to which reported by Rutherfored, Moreside, \& Wong, (2018) reported, it is reasonable to suggest that women with diabetes will experience .

As regards marital characteristics the finding of the present study (table 2) showed that more than half of studied women (57.6.0\%) married from more than ten years and majority of women had child and Regarding to regularity of women sexual intercourse figure (3) revealed that the more than four fifths of the studied women practiced regular sexual intercourse, the present finding were in the same line with Abdel-Rahman Moslehy, Hamido, Samir Metwally \& Husseiny Salama, (2017) who reported that less have of studied women were married more than ten years, the majority of 
them have kids and more than three quarters of women practiced sexual relation by regular way.

More than four fifths of studied women were suffer from desire dysfunction , in relation to arousal, lubricant, orgasm and pain domains, the present studied represent that the majority of studied women had arousal problem, orgasmic problem, lubricant problem and pain during sexual relation and more than four fifths of studied women had problems with satisfaction in their sexual relation. These findings were in accordance with Ezeani, Onyeonoro, \& Ugwu, (2020) in their study on Seventy-five consenting females with type 2 diabetes mellitus (T2DM), who reported that The FSFI scores in the desire, lubrication, and orgasm domains were all lower in the diabetic women and this was statistically significant $(p<0.05)$. The domains of pain and arousal were also lower in the diabetic women, although this was not statistically significant $(p>0.05)$. The proportion of diabetic females who reported problems in the arousal, lubrication, orgasm, and pain domains was higher $(40.0,36.4$, $32.7,29.1)$ than the controls $(27.9,16.2$, 14.7, 19.1; $<<0.05)$. The prevalence of female sexual dysfunction in our study was high. Similarly, the FSFI score was low in women with diabetes.

Regarding to relation between sociodemographic characteristics and female sexual dysfunction of diabetic women in table (5) the present study found that no association between age and sexual dysfunction and it was like Alizadeh, et al., (2013) who reported that there was no significant relation between the sexual function score and age. While Chedraui, et al., ( 2009) disagreed with study finding because who noted that there was a positive correlation between age and female sexual dysfunction and also Nwagha, et al.,( 2014) reported in their study that female sexual dysfunction is common in the university environment, with the highest prevalence occurring in 41-50 years age group.

Also the present study found that no association between the level of education and sexual dysfunction This finding was in accordance with Nwagha, et al., (2014) which reported in their study that educational qualification, Marital status, ethnic group, and religion had no significant effect $(\mathrm{P}<0.05)$ also Butt, Lema, Mukaindo, Mohamoud, \& Shabani, (2019) and Khedr \& Metwally, (2018) reported in their study that no statistical significant regarding their personal characteristics. The finding of the current study were in disagreement with Saeed shakeri, et al., (2012) who showed that educational level positively is associated with score of female sexual dysfunction in all women also Ozcan et al. (2011) and Demirezen, (2006) have found that mean total score of women sexual function scale and educational status were correlated $(\mathrm{P}<$ 0.05).

As regards to women occupation the present study found that no association between the occupation and sexual dysfunction This finding was in the same line with EInashar et al., (2007) who reported in their study that work status and source of income had no impact upon sexual function greatly, although in $28.1 \%$ of respondents, unfavorable economic circumstances were among the aggravating factors for their sexual problems. while the current study disagreed with Abou Khodair, Al-Wafa, Othman, \& Rotab, (2019) who reported in their study that women not working were at higher risk to 
get FSD $(\mathrm{P}<.001)$ with the significant impact of socioeconomic level on having FSD.

The present study that was conducted on type 2 diabetic women and showed that sexual counseling with PLISSIT approach increased the sexual function score and most of its field in women with type 2 diabetes the intervention significantly. PLISSIT model is one of the most widely accepted counseling sexual models that could be useful which created by Annon, (1976), this model of sexual counseling has been performed in various groups of patients including patients with breast cancer, cardiovascular, hysterectomy, and multiple sclerosis, which have been shown to be effective in all cases (Mehrabi, Lotfi, Rahimzadeh, \& Khoei, 2019).

Regarding female sexual function index, the current study in table (8) stated that all domains of sexual function were improved through counseling intervention. This finding was in accordance with study done by Mehrabi, Lotfi, Rahimzadeh, \& Khoei, (2019) on 100 married women aged 35-55 year old with type 2 diabetes referred to endocrinology clinic, who reported in their study that PLISSIT model-based sexual counseling increased all domains of sexual function, except for sexual excitement and pain. Also the results obtained by Sayed Saboula et al (2015) revealed a postintervention improvement in all the dimensions of sexual functioning, including desire, arousal, lubrication, orgasm, satisfaction and pain (with the exception of sexual desire), as well as in the score of body image. Also, khakbazan, et al., (2016) in their study was conducted to evaluate the effectiveness of sexual counseling based on the Permission, Limited Information, Specific Suggestion, Intensive
Therapy (PLISSIT) model on the Sexual Dysfunction (SD) of married sexually active women who suffer from Multiple Sclerosis (MS) reported that utilizing the PLISSIT model as a framework for sexual counseling can improve sexual function in women who are sexually active and suffer from SD due to MS.

Bijlsma-Rutte, Anne, et al., (2017) stated that the PLISSIT-model based intervention significantly improved short-term sexual functioning in women, but not in men with type 2 diabetes with sexual problems in Dutch primary care. More intensive treatment outside primary care may be necessary to improve male sexual functioning. The PLISSIT-model offers a framework that may help GPs to discuss sexual health in diabetes care and another study done by Nejati, Kazemi, Masoumi, Parsa, Karami, \& Mortazavi, (2017) was conducted to determine the effect of counseling based on the PLISSIT model (permission, limited information, specific suggestions, intensive therapy) on sexual function in pregnant women; including 80 pregnant women with gestational age of 24-26 weeks, who found in their study after adjusting for pre-intervention score, there were significant differences between the mean score of sexual function, and all its domains, among experimental and control groups at the fourth week after the intervention $(\mathrm{P}<0.05)$ and stated that sexual counseling based on PLISSIT model improved sexual function in women during pregnancy. Yildiz and Tutuncu (2012) also showed a better sexual functioning three and six months after mastectomy in women who had received PLISSIT-based training, The results of a study conducted by Mansour et al (2011) in Iran also showed a significant difference in the SFI score and the degree of pain before and after a sexual rehabilitation. 


\section{Conclusion}

Based on the results of the present study it could be concluded that; there was an effect of the counseling by using PLASSIT model which carried out during the current study on female sexual function outcomes which manifested by elevating the score of female sexual function index after intervention and follow up compared before intervention. Finally, there were obvious that the counseling intervention have positive effect to enhancement of sexual function among diabetic female.

\section{RECOMMENDATIONS}

A. Considering the importance role of sexual function in family strength, health, and development, it can be Increase awareness of Egyptians about sexuality through counseling session and educational program to discuss sexual dysfunction related to diabetes.

B. Integrate the concept of sexual counseling based on PLISSIT model in addressing sexual dysfunction into undergraduate curricula of faculties of nursing.

C. A nurse should be trained in couple therapy and sexual counseling, it can be claimed that by provide nurses with efficient knowledge about sexuality: its nature, sexual process disorder and management.

D. The media should intensify education on good lifestyles that improve health and better sexual function.

E. Female sexual health remains a muchneglected area in diabetes clinical medicine; however, it is important for psychological and social well-being as well as reproductive function. We aimed to explore the views of women regarding the impact of diabetes on sexual health beyond pregnancy and reproduction.
F. People should improve on their lifestyles to avoid diabetes and sexual dysfunction.

\section{References}

Amanyam, C. T., Yohanna, S., \& Obilom, R. E. (2016). Assessment of sexual dysfunction in patients with diabetes mellitus in the general outpatient clinic of Dalhatu Araf Specialist Hospital Lafia. Nigerian journal of family practice, 7(3), 35-42.

Abdel-Rahman Moslehy, S., Hamido, S., Samir Metwally, N., \& Husseiny Salama, A. (2017). Effect of Adaptation Program about Sexual Dysfunction for Diabetic Women. Egyptian Journal of Health Care, 8(3), 141-154.

Abou Khodair, H., Abo Al-Wafa, H. O., \& Rotab, S. M. M. (2019). Prevalence of female sexual dysfunction in Damietta governorate. The Egyptian Journal of Hospital Medicine, 74(1), 55-62.

Ahmed, M., Gad, M., \& Al-Adlany, M. (2020). Cognitive impairment and depression in patients with diabetic retinopathy. Egyptian Journal of Psychiatry, 41(1), 1.

Alizadeh, N. S., Arasteh, M., Mohsenpour, B., Karimian, F., \& Alizadeh, N. S. (2013). Comparison of sexual dysfunction between diabetic and non-diabetic women. Journal of mid-life health, 4(3), 167.

Al-Rubeaan, K. (2010). Type 2 diabetes mellitus red zone. Int $J$ Diabetes Mellitus, 2(1), 1-2.

Annon, J. $\quad$ S. $\quad$ (1981). PLISSIT therapy. Handbook of innovative psychotherapies, 629, 639. 
Bandeira, D. M., Da Fonseca, L. J. S., Guedes, D. S., Rabelo, L. A., Goulart, M. O., \& Vasconcelos, S. M. L. (2013). Oxidative stress as an underlying contributor in the development of chronic complications in diabetes mellitus. International journal of molecular sciences, 14(2), 3265-3284.

Elyasi, F., Kashi, Z., Tasfieh, B., Bahar, A., \& Khademloo, M. (2015). Sexual dysfunction in women with type 2 diabetes mellitus. Iranian journal of medical sciences, 40(3), 206.

Ezeani, I., Onyeonoro, U., \& Ugwu, E. (2020). Evaluation of Female Sexual Function in Persons With Type 2 Diabetes Mellitus Seen in a Tertiary Hospital in Southeast Nigeria With Emphasis on its Frequency and Predictors. Journal of Sex \& Marital Therapy, 46(2), 170-176.

Fatemi, S. S., \& Taghavi, S. M. (2009). Evaluation of sexual function in women with type 2 diabetes mellitus. Diabetes and Vascular Disease Research, 6(1), 38-39.

Fatima, T., Miyan, Z., Naeem, N., Riaz, M., \& Basit, A. (2020). Foot practices in patients with type 2 diabetes: Where do we stand?. Journal of Diabetology, 11(1), 8.

International Diabetes Federation. IDF Diabetes Atlas. 8th ed. Brussels: International Diabetes Federation; 2017. Available from: http://www.diabetesatlas.org/resources/2017atlas.htm. [Last accessed on 2018 Jul 05].

Jain, S., \& Saraf, S. (2010). Type 2 diabetes mellitus-Its global prevalence and therapeutic strategies. Diabetes \& Metabolic Syndrome: Clinical Research \& Reviews, 4(1), 48-56.
Khedr, N. F. H., \& Metwally, N. S. (2018): Effect of PLISSIT Model Sexual Counseling on Sexual Function among Women with Diabetes.”." IOSR Journal of Nursing and Health Science (IOSR-JNHS), vol. 7, no.4 , 2018, pp 34-42.

Maiorino, M. I., Bellastella, G., \& Esposito, K. (2020): Diabetes and Sexual Disorders. Diabetes Complications, Comorbidities and Related Disorders, 473-494.

Mazzilli, R., Imbrogno, N., Elia, J., Delfino, M., Bitterman, O., Napoli, A., \& Mazzilli, F. (2015). Sexual dysfunction in diabetic women: prevalence and differences in type 1 and type 2 diabetes mellitus. Diabetes, metabolic syndrome and obesity: targets and therapy, 8, 97.

Mehrabi, M., Lotfi, R., Rahimzadeh, M., \& Khoei, E. M. (2019). Effectiveness of sexual counseling using PLISSIT model on sexual function of women with type 2 diabetes mellitus: results from a randomized controlled trial. International Journal of Diabetes in Developing Countries, 39(4), 626-632.

Mohammed, K. A. A. (2020). Efficiency of encapsulated cinnamon oil in the treatment of diabetes in rats."CU Theses.

Ogbera, A. O., Fasanmade, O. A., Chinenye, S., \& Akinlade, A. (2009). Characterization of lipid parameters in diabetes mellitus-a Nigerian report. International archives of medicine, 2(1), 19.

Peter, J., Riley, C. K., Layne, B., Miller, K., \& Walker, L. (2012). Prevalence and risk factors associated with erectile dysfunction in diabetic men attending clinics in Kingston, Jamaica. J Diabetol, 2, 2.

Quinn, C., \& Happell, B. (2012). Getting BETTER: Breaking the ice and warming to the inclusion of sexuality in mental health 
nursing care. International Journal of Mental Health Nursing, 21(2), 154-162

Quinn, C., \& Happell, B. (2012). Getting BETTER: Breaking the ice and warming to the inclusion of sexuality in mental health nursing care. International Journal of Mental Health Nursing, 21(2), 154-162

Rahmanian, E., Salari, N., Mohammadi, M., \& Jalali, R. (2019). Evaluation of sexual dysfunction and female sexual dysfunction indicators in women with type 2 diabetes: a systematic review and metaanalysis. Diabetology \& metabolic syndrome, 11(1), 73

Rezaei-Fard, M., Lotfi, R., Rahimzadeh, M., \& Merghati-Khoei, E. (2019). Effectiveness of Sexual Counseling Using PLISSIT Model to Promote Sexual Function of Women with Spinal Cord Injury: A Randomized Controlled Trial. Sexuality and Disability, 37(4), 511-519

Rutherford, D. J., Moreside, J., \& Wong, I. (2018). Differences in hip joint biomechanics and muscle activation in individuals with femoroacetabular impingement compared with healthy, asymptomatic individuals: is level-ground gait analysis enough?. Orthopaedic journal of sports medicine, 6(5), 2325967118769829.

Udo, I. A., Effiong, J. H., Edet, I. V., Aniedi, U. V., \& Morgan, E. A. (2019). Prevalence and Clinical Correlates of Sexual Dysfunction among Primary Care Diabetes Mellitus Enrollees attending National Health Insurance Scheme (NHIS) Clinic in Uyo, South-South, Nigeria. Jpn J Med, 2, 3

Whiting, D. R., Guariguata, L., Weil, C., \& Shaw, J. (2011). IDF diabetes atlas: global estimates of the prevalence of diabetes for
2011 and 2030. Diabetes research and clinical practice, 94(3), 311-321.

World Health Organization. Global Health Estimates 2016 Summary Tables [cited 2017 Jun 6]. Available at: http://www.who.int/healthinfo/ global_burden_disease/en/.

Wright, D., \& Pugnaire-Gros, C. (2010). Let's talk about sex: Promoting staff dialogue on a mental health nursing unit. Journal for Nurses in Professional Development, 26(6), 250-255

Zhang, P., Zhang, X., Brown, J., Vistisen, D., Sicree, R., Shaw, J., \& Nichols, G. (2010). Global healthcare expenditure on diabetes for 2010 and 2030. Diabetes research and clinical practice, 87(3), 293301. 
المشاكل الجنسية للسيدات المصابة بمرض السكرى : التدخل المشوري

تريزة خليفة جرس جرجس, رجاء على محمد, سعاد عبد السلام رمضان, هند عبد الله السيد عفيفى

تعد المشاكل الجنسية واحدة من المشاكل التي تهم مرضى السكري، ومن الممكن ان المشاكل الجنسية تكون علامة مبكرة لمرض السكرى. لذلك هدفت هذه الدراسة إلى تقييم تأثير جلسات المشوره على المشاكل الجنسية للسيدات المصابات بمرض السكرى. وقد أجريت الدراسة في مستشفي جامعة 6 اكتوبر فى العيادات التعليمية علي 132 سيدة مصابة بداء السكري لايهن مشاكل جنسية وتتطبق عليهن مواصفات العينة. حيث أظهرت نتائج الدر اسة وجود دلالة إحصائية إيجابية بين جلسات المشوره و تعزيز الوظيفة الجنسية بين الإناث المصابات بداء السكري , كما أوصت الدراسة بضرورة إجراء المزيد من الأبحاث لاستكثاف العلاقة بين مرض السكري و الخلل الجنسي للإناث لتحديد العو امل المحتملة لهذا الارتباط. . 